\title{
Natural Log Transformed Area Under the Curve From Dosing to Last Concentration
}

National Cancer Institute

\section{Source}

National Cancer Institute. Natural Log Transformed Area Under the Curve From Dosing

to Last Concentration. NCI Thesaurus. Code C161414.

The natural log transformed area under the curve (AUC) from the time of dosing to the last measurable concentration. 